\title{
Introducción al dossier: Chile, hasta que la dignidad se haga costumbre. Movilización social, proceso constituyente y horizontes de posibilidad post 18 de octubre
}

\author{
Claudio Alvarado Lincopi \\ Pontificia Universidad Católica de Chile, Chile \\ cdalvarado@uc.cl \\ Javiera Robles Recabarren \\ FaHCE-Universidad Nacional de La Plata/ IIGG-UBA CONICET, Argentina \\ libertad.recabarren@gmail.com
}

Chile no da tiempo al descanso y el extrañamiento, no permite mirar de/sde la lejanía y observar detenidamente todo lo acontecido desde el 18 de octubre de 2019, desde esa fecha toda construcción narrativa que permita sustentar medianamente el futuro político del país se desvanece en el aire. Ningún sector político tiene comprada toda la baraja del futuro institucional. Es ahí la condición que nos permite señalar que ad-portas de un proceso constituyente no deja de acontecer aún el momento destituyente iniciado aquel viernes primaveral de octubre del 2019. Todavía habitamos el ejercicio develador, aún vemos como todo lo que brillaba sobre el supuesto oasis chileno se desnuda paso a paso, volviendo la mirada sobre el desierto que realmente reinaba tras el espejismo neoliberal. Así, nuestro dossier surge incompleto, es que las heridas visibles desde la Revuelta son tantas, que probablemente nos tendrán toda la vida observándolas, conociéndolas e idealmente sanándolas. Asumimos esa imposibilidad, acá apenas un respiro de explicaciones, asombros y posibilidades quiméricas.

Son momentos convulsos en Chile, el otrora país "estable" de la región ha develado su verdadero rostro. La política del marketing, esa donde las agencias de publicidad, las consultoras del lobby y las empresas de encuestas gobiernan desde la prensa hegemónica, ya no da el ancho, desde el 18 de octubre, de algún modo, toda comunicación estratégica no logra revertir la porfiada realidad de desigualdades y jerarquías. Un rayado -graffiti- de la Revuelta condensa este nuevo momento político: "Estamos peor, pero estamos mejor; porque antes estábamos bien, pero era mentira, ahora estamos mal, pero es verdad”.

Desde el 18 de octubre la grieta que permite observar el verdadero cariz del país se ha expandido, la desigualdad y la pobreza se evidencian con mayor claridad, y bajo la pandemia ello ha quedado completamente develado, profundizando la mirada sobre los recovecos olvidados de la "transición democrática" y situando nuevamente el hambre y la muerte como experiencias cotidianas en las zonas de marginalidad, ya reflexionaremos sobre ello. Por otro lado, los privilegios de las élites ya no pasan del todo desapercibidas y la ciudadanía escruta permanentemente a quienes gobiernan, allí emerge una posibilidad democratizadora ineludible. El movimiento feminista, el movimiento socioambiental y los movimientos indígenas también hacen lo suyo para expandir los horizontes de posibilidad del debate público.

Los cerrojos de la "democracia de los acuerdos" se comenzaron a abrir, la fórmula del binomio político entre las fuerzas de la Concertación y la Derecha, que permitió estabilidad neoliberal durante los últimos 30 años, se comenzó a fracturar. Es que la impugnación de la Revuelta fue clara: "no son 30 pesos, son 30 años". Porque supuestamente el origen del estallido social, en un primer momento, eran apenas 30 pesos de 
alza del transporte urbano en Santiago, que por cierto se encuentra también privatizado, pero rápidamente la movilización comenzó a señalar que no se trataba ya de números más o números menos, la reflexión fue sobre el modelo, en su dimensión económica, política y cultural, haciendo de la impugnación un fenómeno denso, complejo, inatrapable para formulaciones exiguas. Y fue justamente aquella densidad la que en pocos días logró pasar de una queja por 30 pesos a la demanda por una Nueva Constitución. Ese salto fue cualitativo, y un gobierno de derechas tuvo que dar su mano a torcer para cambiar la Constitución que ellos mismos habían formulado y establecido en 1980, en plena dictadura cívico-militar.

Nosotros/as creemos que detrás de aquellas semanas de aceleración histórica, porque así se vivieron, como un vendaval temporal que vino a modificar lo que parecía inamovible, son el resultado de décadas de reflexión y lucha de diversas expresiones de los movimientos sociales y políticos del país. Cada una de ellas hicieron aportes cruciales para expandir la crítica, desde los/as estudiantes a los/as indígenas, de las comunidades afectadas por el extractivismo hasta las disidencias sexo-genéricas, desde el feminismo al movimiento obrero, todos/as gestaron desde los propios años dictatoriales impugnaciones y contrariedades al modelo neoliberal, y posteriormente a la democracia restringida.

De este modo, desde las luchas de los pueblos, el país se ha venido democratizando, no institucionalmente, no orgánicamente, pero sí de facto. Prueba de ello fue la reciente aprobación de una ley que permitió a los afiliados a las Administradoras de Fondos de Pensiones (AFP) sacar el 10\% de sus ahorros, para paliar las consecuencias económicas de la crisis y la pandemia. El día anterior a la votación en el Congreso los cacerolazos y las barricadas se hicieron sentir en todo el país, develando que la politización en curso es un reclamo democratizador, hay ansias de participar en el devenir del país. Por cierto, este 10\% para Chile, donde el ladrillo neoliberal se fundó a sangre y fuego no es algo menor. Las AFP son el pilar fundamental del sistema financiero instalado en la dictadura cívico-militar, y la derecha rasgó todas las vestiduras para evitar que los y las trabajadoras pudieran acceder a sus ahorros, la derecha, las AFP y el empresariado decían incluso que la economía se iría a pique, pero nada de eso ocurrió. Actualmente son millones los que están retirando parte de sus ahorros para enfrentar la crisis económica, y se siente como un triunfo de la Revuelta y poder democratizador.

Con ello, radicalizar la democracia se comienza a avizorar por amplios sectores como una posibilidad para enfrentar el empobrecimiento, es decir, la pobreza se politiza, ya no es producto de un escenario fortuito, sino que encuentra hebras explicativas en el marco del modelo político y económico. Y la pobreza y el hambre, en contexto de pandemia, se han tomado nuevamente el debate. Desde hace décadas que estas palabras no aparecían en la discusión política cotidiana, la intelligentia neoliberal que fundó su narrativa societal sobre la subjetividad del consumidor, sacó por años del mapa político a los/as pobres, todo sobre la base del endeudamiento. Es lo que precisamente reflexiona Vicente Orellana en su artículo "La deuda interna de la democracia y su crisis en el estallido de octubre. Precios, salarios y deuda morosa en el Chile actual", indicando que, si bien Chile mantuvo por los últimos 30 años una política macroeconómica positiva, ello no ha favorecido a los sectores populares y las clases medias, generando una insatisfacción que se desplegó durante el estallido social iniciado el 18 de octubre.

Si bien la punta de lanza de la Revuelta fueron temas económicos, rápidamente la reflexión fue madurando hacia las diversas formas de cómo se expresa la desigualdad y la opresión. El movimiento feminista para noviembre ya lograba instalar la dimensión patriarcal del neoliberalismo y la democracia restringida, el Colectivo Las Tesis fue fundamental para aquella profundización crítica, en este punto del desarrollo de la Revuelta el canto "el patriarcado es un juez" invadía el movimiento feminista internacional. Chile durante algunas semanas, gracias al feminismo, fue el centro del mundo. La pulsión feminista de la Revuelta es lo que precisamente revisa Karelia Cerda en su trabajo "Estallido Social e Historia de las Mujeres: construcción de una genealogía feminista en Chile”. Todo esto permitió que fuera ineludible que el Proceso Constituyente no tuviera en su elaboración la paridad de género, convirtiendo la próxima Constitución de Chile la primera en el mundo que sería redactada por la misma cantidad de hombres y mujeres. 
Otro de los nudos problemáticos que se venían desnudando previo al 18 de octubre son los efectos depredadores del extractivismo. Muchas zonas del centro del país han sufrido sequías históricas que, junto con el saqueo empresarial materializado en la privatización del agua, mediante un Código de Aguas heredado de la dictadura, han generado una crisis social en muchos valles del país. A esto se le suma la tipificación gubernamental para determinados territorios explotables y contaminables como "zonas de sacrificio", la concreción más perversa de un régimen de acumulación que depreda y contamina sin miramientos humanos y ambientales. Sobre esto nos permitirá profundizar Javier Zuñiga en su trabajo "La historicidad de una alternativa ecosocial: origen y características de la crisis socioambiental en el marco del 18 de octubre", donde nos sumerge a la dimensión extractivista del neoliberalismo y sus consecuencias en la precarización, devastación y conflictividades sociales y ambientales que también explican la Revuelta y sus posibles devenires políticos para la transformación del modelo en Chile.

Ahora bien, una vez desplegados los repertorios de la movilización desde el 18 de octubre, son posibles de observar una serie de fenómenos tanto lamentables como esperanzadores. Las ciudades comenzaron a ser escenarios de conflicto y creación, de ello hablan de alguna manera los tres siguientes textos de nuestro dossier.

En primer término, es de internacional conocimiento la brutal represión que desarrolló el gobierno de Sebastián Piñera contra la Revuelta. Desde la primavera desde el 2019 hasta el inicio de las cuarentenas en marzo del 2020, fueron miles los/as encarcelados, los/as golpeados e incluso torturados/as, cientos/ as sufrieron la mutilación de sus ojos producto de los balines de Carabineros de Chile y, por cierto, lamentablemente, también hubo asesinados/as. Ese fue el triste precio que tuvieron que pagar los pueblos de Chile por ampliar la democracia e intentar modificar el modelo neoliberal, y es hacia donde precisamente nos sumerge Carmen Pinto Luna con su texto "Estallido Social, Memoria y Derechos Humanos". El 18 de octubre se comenzó a trenzar las memorias de luchas y represiones dictatoriales, con las actuales batallas por los Derechos Humanos en el país.

En contraste con la represión que buscó cancelar el poder creativo y utópico de la Revuelta, se desplegó su contracara inventiva sobre la ciudad. La urbe de tendencia grisácea y homogeneizante tuvo un devenir barroco mediante el arte, la performance, el grafiti, el renombramiento de los espacios públicos de la ciudad. Dos espacios en Santiago de Chile entraron en clara confrontación de sentidos: el Centro Cultural Gabriela Mistral (GAM) y la Plaza Dignidad (ex Plaza Italia).

Elías Sánchez, quien ha investigado detenidamente el GAM, nos ofrece en su artículo "La desobediencia civil de las memorias: ¿Debe ser conservado el Centro Cultural Gabriela Mistral callejero del Estallido Social?" una interesante reflexión sobre las disputas de la memoria inscritas en aquel histórico edificio de la ciudad, al tiempo que propone un quehacer sobre este espacio en disputa que el autor define como un "patrimonio difícil". Sin duda, los combates por la historia y la memoria se abrieron radicalmente desde el inicio de la Revuelta aquel 18 de octubre.

Precisamente, sobre estas disputas por el espacio público y su relato cerraremos nuestro dossier. Mediante un texto de Ivette Quezada y Claudio Alvarado llamado "Repertorios anticoloniales en Plaza Dignidad: desmonumentalización y resignificación del espacio urbano en la Revuelta", nos adentraremos a unos de los fenómenos llamativos de la Revuelta, que luego se han reproducido en otras partes del mundo, los ejercicios de desmonumentalización. Observando los renombramientos y las saturaciones estéticas sobre un punto central de la ciudad que fue renombrado como Plaza de la Dignidad (ex Plaza Italia), la y el autor introducen conceptos que nos permiten pensar otro urbanismo posible, menos afincado a las lógicas del mercado y más cercano a los modos barrocos de habitar la ciudad y sus centros de encuentro societal.

Con todo, nuestro dossier busca dar un panorama general tanto a los nudos críticos de desigualdad y opresión que permiten comprender los por qué de la Revuelta, como las posibilidades democratizadoras y antineoliberales que emergen al calor de la movilización. Todo esto será puesto a prueba en la coyuntura constituyente que se avecina, observaremos las capacidades de los movimientos sociales y políticos para abrir decididamente los marcos de la democracia. Aunque claro, todo esto se está desenvolviendo en medio de una 
pandemia y de una crisis económica que tiene a amplias capas de los pueblos de Chile habitando entre la desesperanza y los gestos de dignidad. Difícil entonces no desarrollar unas últimas reflexiones sobre el actual escenario, donde el impulso de la Revuelta se ha transformado e invadido las ollas comunes de los territorios populares afectados por la peor cara de la pandemia.

\section{DESTITUYENDO Y CONSTITUYENDO EN MEDIO DE UNA PANDEMIA}

Resulta complejo escribir sobre la segregación de la muerte y el hambre sin remitirnos a la década de los ochenta, ya sea por las lamentables cifras económicas que hemos conocido en los últimos meses y que nos remonta a esa década ${ }^{1}$, o por la efervescencia de lucha de las clases populares. La irrupción de una memoria del hambre, pero también de la sobrevivencia y la solidaridad, pareciera que han surgido de forma natural ante una situación similar a la vivida en dictadura, memorias que surgieron luego de un largo hiato.

Pareciera que la historia y la memoria de la pobreza, el desempleo y el hambre transcurrieron de manera subterránea en el fluir de las múltiples memorias que convivieron, muchas veces entre tensiones y conflictos, durante la transición a la democracia. Fue el relato del milagro económico y del exitismo neoliberal el que predominó en nuestros noventas y dos mil, ocultando en su triunfalismo la contracara que tuvo el shock neoliberal en la calidad de vida de los pueblos, como también en la normalización sofocante de la desigualdad y la injusticia. Borrando de la palabra pública las historias del $40 \%$ de desempleados/as que dejó la crisis del 82 y el 30\% de quienes vivían en extrema pobreza para 1986 (Hardy, 1986, p. 23-24), o aquellas historias del $79 \%$ de mujeres en edad de procrear que se encontraban bajos los estándares de peso mínimo durante los primeros años de la década (Bruey, 2018, p. 73).

Como bien se presentó, la Revuelta vino a poner en jaque, a revelar las desigualdades estructurales de nuestra democracia. Sin embargo, y más allá de lo que se pudo pensar como una oportunidad para el gobierno de reposicionar su liderazgo político, la pandemia irrumpió en nuestras fronteras terminando por mostrar, de forma radical, la inequidad de vivir en Chile. A pesar de que los primeros contagios se concentraron en las comunas más ricas de la capital, no pasó mucho para que la tasa de incidencia y de mortalidad fueran el correlato de una sociedad segregada: si mientras Vitacura -la comuna más rica de Santiago- tiene una tasa de mortalidad de 61 por mil habitantes, Puente Alto ostenta uno de los primeros puestos con 573 por cada mil habitantes, La Florida 472 y Recoleta 301, algunas de las comunas más pobres de la capital (MINSAL, 2020, p. 41).

La muerte en tiempos de pandemia también ha transformado los ritos funerarios, los que en sectores populares han intervenido la espacialidad poblacional. En los barrios de la capital las/os sujetos se resisten a vivir la muerte en soledad, los globos blancos en las rejas de las casas de la cuadra son un aviso de que murió un vecino/a, los pétalos de flores en el suelo son huella que en ese camino pasó el carro fúnebre y la población salió a despedirlo/a desde sus casas. El paisaje cotidiano y cómo esta nueva ritualidad lo ha teñido, no son sólo una expresión de la tristeza por la pérdida de los seres queridos de quien fallece, sino también nos habla de la experiencia de clase de vivir la pandemia.

En comunas con una alta tasa de mortalidad la muerte se ha vuelto cotidiana, presente y posible, y las/os sujetos han respondido a experienciarla de forma colectiva a pesar de los impedimentos sanitarios. En una sociedad desigual como la chilena, cuando son cerca de diez vecinos/as en dos semanas en un barrio, cuando las personas se preguntan “¿quién murió ahora?”, la muerte es parte de la vida para algunos/as, para otro/as tanto/as sólo es una escasa probabilidad.

Si las cifras de desempleo y destrucción de puestos de trabajo nos recuerdan la crisis económica de 1982, su correlato, la experiencia límite del hambre, también emerge en la memoria colectiva de las generaciones que fueron víctimas de este tipo de violencia estructural. Y en parte la responsabilidad recae una vez más en la ausencia de políticas públicas que resguarden la escasa seguridad social de la población chilena, generando 
una sensación de abandono en las clases populares: cumplir con la cuarentena y no recibir ningún ingreso o salir a trabajar de manera informal y estar expuesto a contagiarse y, eventualmente, morir.

A diferencia de lo ocurrido en la mayoría de los países, donde los gobiernos en general optaron por aumentar el gasto público para ir en ayuda de los y las ciudadanas, asegurando así el cumplimiento del aislamiento obligatorio, en el caso chileno la decisión del gobierno fue apegarse una vez más a su estricta política económica neoliberal. Es posible que desde la dictadura no se haya presentado de manera tan visible y desgarradora el escaso valor que tiene la vida para un modelo económico como el nuestro, en el que se priorizan los indicadores macroeconómicos por sobre las condiciones de vida de las personas.

El 18 de mayo, dos meses con sus trabajos paralizados y tres días después de ser decretada cuarentena obligatoria en la Región Metropolitana, habitantes de la comuna de El Bosque salieron a las calles para protestar ante la desesperación de no tener recursos para alimentar a sus familias, reclamando ayuda al gobierno central y al municipio. En los días siguientes se plegaron otras de las comunas más vulnerables de la capital, como La Pintana, tres días después el presidente Sebastián Piñera anunció la entrega de cajas de mercadería como parte de un plan de ayuda denominado "Alimentos para Chile".

Este es uno de los ejemplos posibles de encontrar en cómo el gobierno ha administrado una pandemia que inhabilita a las/os sujetos a trabajar, en un país con una seguridad social insignificante, donde difícilmente las personas pueden sostenerse sin estar insertos/as en el mercado laboral. Si bien gran parte de las medidas aplicadas han terminado en trasladar el costo de la crisis sanitaria a las y los trabajadores, es preciso aclarar que, en su mayoría, las medidas fueron anunciadas luego de protestas, cacerolazos masivos, barricadas y corte de calles. Como una suerte de recordatorioal gobierno y al Congreso que el cambio en la subjetividad de las clases populares no se durmió con la pandemia.

Las ollas volvieron a sonar, en la protesta y en las cocinas populares que se han encendido en diversas comunas del país. Ante la ausencia de recursos para comprar alimentos y la posibilidad real del hambre, las ollas comunes tan características de la década de los ochenta como "estrategia de sobrevivencia" de las poblaciones (Schkolnik y Teitelboim, 1988, p. 31), parecieran ser que surgieron de forma rápida y espontánea en el presente.

Pero ¿̨cómo situar y poner en sentido esta naturalidad aparente en la organización masiva de ollas comunes en la capital, que han ido aumentando en número y cantidad de raciones entregadas?², ¿Por qué frente a una crisis económica provocada por una pandemia que exige evitar el contacto estrecho, se decide cocinar colectivamente para sus propias familias y para la comunidad?

Keli, dirigenta de 66 años de la junta de vecinos Vientos del Cerro en una población en la ladera del Cerro San Cristóbal en la comuna de Recoleta, decidió convocar a algunas vecinas y levantar una olla común durante la segunda semana de abril. Fue una de las primeras ollas comunes organizadas en Recoleta y que aún continúa en funcionamiento. En estos cuatro meses han aumentado en días, cantidad de raciones entregadas y perfeccionado las redes de apoyo comunitarias, como también la logística que requiere llevar adelante una olla común: el menú, los recursos, la organización interna de sus participantes, la compra y distribución.

A pesar de ser la primera olla común que organizó Keli, su trayectoria de vida está mediada por la historia reciente chilena y la experiencia dictatorial en las poblaciones. En medio de la cocina y la preparación de tallarines con salsa, nos relató sobre su experiencia en los trabajos voluntarios durante la Unidad Popular, los allanamientos constantes en su población, de cómo tomaron detenidos a su esposo y padre y a todos los hombres del barrio el día del golpe de Estado. De su propia memoria del hambre, de lo que significó alimentar a siete personas en su familia, de la escasez, la precariedad y la sobrevivencia. También de cómo participó de las ollas comunes que se organizaron en el barrio y de las estrategias de subsistencia entre las vecinas y vecinos de su comunidad ${ }^{3}$.

Por otra parte, retomando los trabajos que abordaron las ollas comunes de los ochenta, como el de Clarisa Hardy (1986) o la pobreza en las poblaciones del Programa de Economía del Trabajo (Schkolnik y Teitelboim, 1988), es posible encontrar importantes apuntes sobre su caracterización que recobran sentido 
en la experiencia presente: son una organización social de subsistencia, popular, territorial, basada en el trabajo colectivo y con una estabilidad fluctuante según los cambios en la situación individual de sus miembros o estructural de las condiciones económicas del país.

No obstante, cabe precisar que una de las características de las ollas comunes es que nacen producto de las condiciones de vida provocadas por las crisis económicas que imposibilita la inserción de los sujetos al aparato productivo. Si ayer fueron las consecuencias que tuvo la crisis del shock neoliberal y, posteriormente, la crisis de la deuda, en el presente lo que impide la posibilidad de trabajar es un factor externo. Situar los aspectos político-económicos en el análisis posibilitan alejarnos de aquellas interpretaciones que buscan romantizar y despolitizar este tipo de estrategias de sobrevivencias, relatos bastante difundidos por los medios de comunicación en las últimas semanas.

De ahí que, la potencialidad política y simbólica que tuvo la proyección de la palabra "Hambre" en el Edificio Telefónica por Delight lab en la noche del 18 de mayo ${ }^{4}$, el día de las protestas de El Bosque y que posteriormente fue censurada por "desconocidos" en pleno toque de queda, puso en jaque precisamente el relato del "milagro chileno" y del exitismo neoliberal ya venido a menos desde la Revuelta. De alguna forma, la ausencia de legitimidad de la palabra de los/as más pobres del país durante la transición - y en este caso de "la" palabra-, fue recuperada, iluminada y proyectada en un recordatorio que la memoria del hambre estuvo lejos de ser olvidada.

Un último apunte que quisiéramos relevar, que seguramente será retomado con la rigurosidad académica que merece por otros y otras investigadoras, es la participación mayoritaria de mujeres en la organización de las ollas comunes. Son las mujeres quienes se han reunido alrededor de las cocinas para entregar una solución colectiva a sus problemas individuales, gestionando recursos, organizando el trabajo del grupo, creando redes comunitarias de cooperación, sumado a las exigencias sanitarias producto de la pandemia 5 .

Las causas pueden ser múltiples y, seguramente, obedecen a aspectos estructurales del patriarcado, como son la división sexual del trabajo, la feminización de la pobreza en Chile, el importante número de hogares monoparentales liderados por mujeres y que se concentran en su mayoría en las clases populares, entre otros ${ }^{6}$. No obstante, y tomando en consideración todos estos antecedentes, nos parece importante también relevar la politización de lo privado que se genera en estas cocinas populares y, a su vez, reponer el valor del trabajo doméstico y reproductivo como una pieza fundamental de la economía de las familias y del país.

Como un ejercicio reflexivo para repensar los binarismos y observar con los anteojos del género más allá de las divisiones entre lo público y lo privado. Poder mirar aquellos lugares del tiempo donde la vida transcurre, en las cocinas donde se transmiten experiencias, memorias, saberes y se construye comunidad. Porque la memoria del hambre, de la represión y los allanamientos, está tejida junto a las memorias de las resistencias, la organización y la dignidad, transmitidas mientras se preparan tallarines con salsa en una olla común en una población de la periferia santiaguina.

La fragilidad del tiempo iniciado el 18 de octubre ha posibilitado que las memorias subterráneas de nuestro pasado cercano, de las experiencias individuales de quienes vivieron el golpe de Estado y la dictadura militar, hayan teñido nuevamente los relatos cotidianos, en una mezcla no sin tensiones e, incluso, en ocasiones como relatos corales con escasa armonía. Sin embargo, cuando nos encontramos que las narraciones como las de Keli no son excepcionales, es posible entonces urdir algunos hilos entre la experiencia vivida y las decisiones del presente.

No quisiéramos proponer con esto mecanicismos simplistas, pero sí dar cuenta de una cierta transmisión intergeneracional de las memorias de la resistencia colectiva de las poblaciones del Chile dictatorial. A modo de apuntes, para continuar pensando en cómo aquellas memorias subterráneas surgieron de alguna forma en estas expresiones de organización social y territorial. Lo que nos ha demostrado la organización poblacional hasta el momento es que, ante la remota o cercana posibilidad de revivir nuevamente la experiencia traumática del hambre, levantar ollas comunes al calor del sentido comunitario que se recuperó y reapropió en la Revuelta, resultó más natural de lo que se pudo pensar. 
En un tiempo que nos obligó a reflexionar en todo lo que creíamos hasta este punto, invitamos a leer los trabajos aquí presentados, fraguados al calor de los acontecimientos. Como nota testimonial de lo que implicó escribir en un tiempo bisagra, en medio de la coyuntura, en tiempos convulsos donde las certezas fueron difuminadas en la explosión de la protesta y en la incertidumbre de un virus del que aún no existe cura. Más allá de presentar respuestas a los múltiples por qué que nos han invadido, es tomar de nuestras diversos enfoques y disciplinas, de la historia reciente y la memoria, herramientas interpretativas para buscar poner en sentido la experiencia vivida, con el fin último de entregar algunas pequeñas puntadas en este tejido tan complejo que es el periodo abierto desde ese viernes 18 de octubre de 2019.

\section{REFERENCIAS}

Bruey, A. (2018). Bread, Justice, and Liberty: Grassroots Activism and Human Rights in Pinochet's Chile. Wisconsin: University of Wisconsin Press.

Bruna, J. (6 de julio de 2020). Participación social de mujeres en tiempos de hambre: "La olla no nos va a salvar, la olla nos va a hacer sobrevivir”. El Mostrador. Recuperado de https://www.elmostrador.cl/braga/2020/07/06/parti cipacion-social-de-mujeres-en-tiempos-de-hambre-la-olla-no-nos-va-a-salvar-la-olla-nos-va-a-hacer-sobrevivir/

Encuesta UC: 2,3 millones de chilenos perdieron su empleo en los últimos 12 meses (13 de agosto de 2020). Radio Cooperativa. Recuperado de https://cooperativa.cl/noticias/pais/trabajo/cesantia/encuesta-uc-2-3-millones-de -chilenos-perdieron-su-empleo-en-los-ultimos/2020-08-13/115942.html

Feminización de las ollas comunes: estudio busca dimensionar la alta presencia de mujeres en las iniciativas solidarias surgidas en la pandemia (17 de agosto de 2020). El Mostrador. Recuperado de https://www.elmostrador.cl/braga/2020/08/17/feminizacion-de-las-ollas-comunes-estudio-busca-dimensi onar-la-alta-presencia-de-mujeres-en-las-iniciativas-solidarias-surgidas-en-pandemia/

Hardy, C. (1986). Hambres + Dignidad = Ollas Comunes. Santiago: Programa de Economía del Trabajo - Academia de Humanismo Cristiano.

Ministerio de Salud, Gobierno de Chile (2020). Informe Epidemiológico. Enfermedades por SARS-CoV-2 (COVID-19). Chile 14 agosto 2020 (n42). Departamento de Epidemiología. Recuperado de http://www.min sal.cl/wp-content/uploads/2020/08/Informe-Epidemiológico-40.pdf

Schkolnik, M. y Teitelboim, B. (1988). Pobreza y desempleo en Poblaciones. La otra cara del modelo neoliberal. Santiago: Programa de Economía del Trabajo - Academia de Humanismo Cristiano.

Trabajo doméstico no remunerado: $40 \%$ de los hombres destinó 0 horas a labores del hogar, en tanto las mujeres realizaron 9 horas más que ellos (14 de agosto de 2020). El Mostrador. Recuperado de https://www.elmostrador.cl/braga/2020/08/14/trabajo-domestico-no-remunerado-40-de-los-hombres-des tino-0-horas-a-labores-del-hogar-en-tanto-las-mujeres-realizaron-9-horas-mas-que-ellos/

\section{Notas}

1 Según la última encuesta sobre empleo realizada por el Centro de Estudios Longitudinales UC, en el año transcurrido se han perdido 2,3 millones de empleos, equivalente al $25 \%$ de todos los trabajos en el país. El director del centro de estudios advierte que posiblemente estemos ad portas de una crisis del empleo superior a la de 1982. Si se suman los/ as trabajadores desocupadas, más los/as inactivas y quienes están bajo la ley de seguridad del empleo, el desempleo real llegaría a $31 \%$.

2 La comuna de Recoleta, a modo de ejemplo, pasó de tener alrededor de 23 ollas comunes en mayo, a las 57 ollas que entregan 18 mil raciones semanales aproximadamente (datos facilitados por la Coordinadora de Ollas Comunes de Recoleta).

3 Entrevista a "Keli", realizada por Javiera Robles Recabarren y Camila Medina López, sábado 8 de agosto 2020.

4 Sobre la censura a la intervención lumínica, ver: https://www.24horas.cl/coronavirus/estudio-luminico-que-proyectohambre-en-edificio-de-telefonica-acusa-censura-y-anuncia-recurso-de-proteccion- 4190598 
5 La feminización de las ollas comunes ha sido reporteada por medios como El Mostrador, donde documentaron la participación generalizada de mujeres en las ollas del barrio de San Borja en la comuna de Santiago y en La Cisterna. Asimismo, Fundación Vértice, integrado por urbanistas de la Universidad de Chile, junto a ONU Mujeres están realizando un catastro de las organizaciones de subsistencia para documentar la feminización y el impacto que tiene la crisis en las mujeres.

6 La última encuesta del Centro de Estudios Longitudinales UC también relevó la distribución por género del trabajo doméstico no remunerado, reafirmando en cifras cómo la pandemia ha profundizado las desigualdades sexo genéricas en la administración de lo cotidiano: el 38\% de los hombres destinó 0 horas semanales a realizar labores domésticas y el $57 \%$ dedicó ninguna hora al cuidado de las y los niños del hogar. 